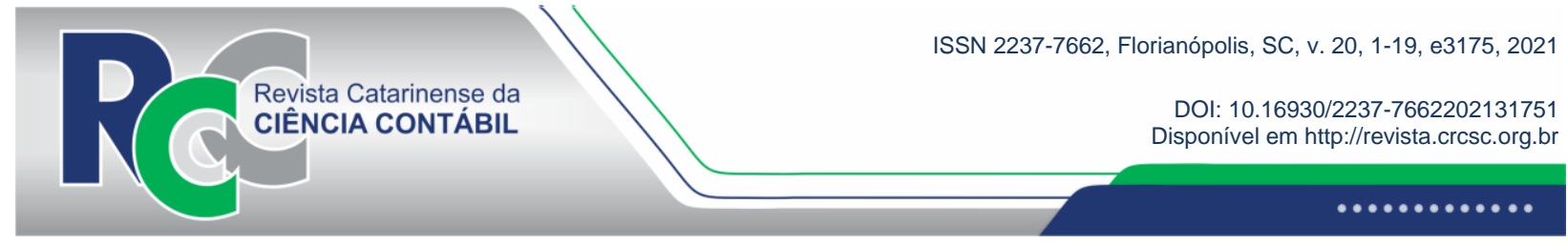

\title{
APRENDIZAGEM BASEADA EM PROJETOS NA PÓS-GRADUAÇÃO EM CIÊNCIAS CONTÁBEIS
}

\section{PROJECT-BASED LEARNING IN AN ACCOUNTING GRADUATE PROGRAM}

\author{
TAÍS DUARTE SILVA \\ Universidade Federal de Uberlândia. Endereço: Avenida João \\ Naves de Ávila, 2121 | Santa Mônica | 38408-100 | \\ Uberlândia/MG | Brasil. \\ (1) https://orcid.org/0000-0002-5972-8851 \\ taisduartes@yahoo.com.br
}

\section{EDVALDA ARAÚJO LEAL}

Universidade Federal de Uberlândia. Endereço: Avenida João Naves de Ávila, 2121 | Santa Mônica | 38408-100 | Uberlândia/MG $\mid$ Brasil.

(1) https://orcid.org/0000-0002-7497-5949

edvalda@ufu.br

\section{RESUMO}

Considerando a relevância que a escolha de uma metodologia de ensino pode ter no aprendizado dos alunos, a presente pesquisa teve como objetivo identificar benefícios e limitações da aprendizagem baseada em projetos. Para alcance do objetivo proposto, investigou-se a aplicação do método na disciplina de Análise de Custos em um Programa de Pós-Graduação em Ciências Contábeis. Em termos metodológicos utilizou-se análise documental, observação, aplicação de questionário e grupo focal com os estudantes. A análise realizada considerou o desenvolvimento de todas as etapas da metodologia proposta pela literatura, destacando a percepção dos discentes, de forma descritiva e qualitativa. Como resultados da pesquisa, verificou-se que a oportunidade de experienciar a prática é o benefício mais enfatizado pelos discentes, ressaltando-se ainda o desenvolvimento da autonomia, o que necessário para a solução do problema proposto no projeto. No que se refere às limitações, destacam-se o tempo demandado para desenvolvimento dos projetos, bem como a necessidade de lidar com situações diversas que podem surgir durante o processo de investigação e elaboração dos projetos. Os resultados encontrados contribuem ao apresentar a metodologia de aprendizagem baseada em projetos como uma oportunidade para que os discentes desenvolvam teoria e prática, vivenciando questões reais relacionadas à atuação profissional. Ressalta-se como limitações da pesquisa o tamanho da amostra, a qual contemplou apenas uma turma durante um semestre e avaliou somente a visão de discentes. Entende-se que essas limitações poderão ser consideradas em estudos futuros, de modo a ampliar a amostra e realizar análises comparativas entre turmas, em diferentes períodos, abrangendo também a visão de docentes.

Palavras-chave: Aprendizagem. Projetos. Custos. Ciências Contábeis.

\footnotetext{
Editado em português e inglês. Versão original em português.
}

Recebido em 1/6/2021. Revisado em 26/7/2021. Aceito em 26/8/2021 pelos Prof. Dr. Sérgio Murilo Petri (Editor-Chefe) e Prof. Dr. Sandro Vieira Soares (Editor Adjunto). Publicado em 30/9/2021.

Copyright $@ 2021$ RCCC. Todos os direitos reservados. É permitida a citação de parte de artigos sem autorização prévia, desde que identificada a fonte. 


\begin{abstract}
Considering the relevance of choosing a teaching methodology on student learning, this study aimed to identify the benefits and limitations of project-based learning. In order to reach the proposed objective, we investigated the method's application in the Cost Analysis course at a Graduate Program in Accounting. The methodology employed included document analysis, observation, questionnaire application, and a focus group with the students. In addition, the analysis considered the development of all the methodology steps proposed by the literature, descriptively and qualitatively highlighting the students' perceptions. As research results, we verified that the students' opportunity to experience the practice is the benefit most emphasized. Furthermore, we highlight autonomy development, which is essential to solving the problem proposed in the project. Regarding the limitations, the time required to develop the projects stands out, and the need to deal with diverse situations that may arise during the projects' investigation and elaboration process. The results contribute by presenting the project-based learning methodology as an opportunity for students to develop theory and practice, experiencing real issues related to professional practice. Among this study's limitations we highlight the sample size, which included only one class during one semester and evaluated only the students' perspective. It is understood that these limitations may be considered in future studies to expand the sample and make comparative analyses between classes in different periods, also covering the view of teachers.
\end{abstract}

Keywords: Learning. Projects. Costs. Accounting.

\title{
1 INTRODUÇÃO
}

A aplicação de metodologias ativas no ensino tem sido discutida como forma de implementar mudanças que propiciem a participação mais autônoma do estudante em seu próprio aprendizado (Berbel, 2011). Com o uso dessas metodologias, espera-se ter um ambiente mais dinâmico de ensino, no qual o professor tenha um papel de facilitador e haja maior envolvimento dos alunos (Farias, Martin \& Cristo, 2015).

Metodologias de ensino consideradas inovadoras possibilitam ao aluno experiências com o mundo real, proporcionando o aprendizado e o desenvolvimento de habilidades (Nicolaides, 2012). Na visão de Morán (2015), a escolha da metodologia deve estar coerente com o objetivo que se espera alcançar. Para exemplificar, o autor cita que, se a intenção é buscar mais proatividade do estudante, deve-se utilizar algum método que apresente situações-problema conduzindo os mesmos a tomar decisões e avaliá-las.

Dentre as diversas metodologias ativas propostas na literatura educacional, investiga-se, na presente pesquisa, a aprendizagem baseada em projetos (ABP). Esse tipo de aprendizagem possibilita um aprendizado que tem como base a investigação de problemas reais, os quais poderão ter mais significado para os estudantes e, por consequência, propiciar um ambiente mais favorável à aquisição do conhecimento (Behrens, 2014). A aprendizagem baseada em projetos é constituída pelo uso de projetos que irão demandar dos estudantes cooperação para resolver situações com as quais eles possam se deparar relacionados à temas multidisciplinares (Bender, 2014). Além disso, essa modalidade de aprendizagem possibilita não somente o aprendizado, mas também o desenvolvimento de competências, tais como, o trabalho em equipe, a comunicação e o pensamento crítico (Frezatti \& Martins, 2016).

Alguns estudos (Bento, 2011; Berbel, 2011) destacaram que a metodologia ABP pode propiciar o maior interesse dos estudantes, pois haverá a necessidade de investigações e busca de soluções para as situações-problema apresentadas. Entretanto, ainda há dúvidas quanto aos 
resultados positivos que a metodologia pode proporcionar no processo de aprendizado (Kokotsaki, Menzies \& Wiggins, 2016), o que indica a necessidade de novos estudos que investiguem os possíveis benefícios da ABP na aprendizagem (Guo, Saab, Post, \& Admiraal, 2020).

Observa-se também na literatura que a aplicação da ABP pode ocorrer nas mais diversas áreas acadêmicas do ensino superior (Guo et al, 2020). Contudo, ressalta-se no presente trabalho a perspectiva de Smith e Gibson (2016), os quais destacam o potencial da ABP para área de negócios, visto que discentes dessa área denotam preferência de aprender por meio de conteúdos práticos. Ainda referente a área de negócios, especificamente em cursos de graduação de Ciências Contábeis há evidências (Azevedo, Araújo \& Medeiros, 2017; Silva, Araújo, Vieira \& Bispo, 2018) de que o uso da ABP promove o desenvolvimento de competências profissionais, aprimorando a formação dos graduandos.

$\mathrm{Na}$ perspectiva de contribuir com a literatura anterior, especialmente no que se refere à educação contábil, pretende-se, na presente pesquisa, investigar os benefícios e limitações da aplicação do método Aprendizagem Baseada em Projetos na disciplina Análise de Custos oferecida em um Programa de Pós-Graduação em Ciências Contábeis.

Para tanto, pretende-se analisar o método ABP à luz da Teoria da Aprendizagem Experiencial, a qual defende a perspectiva de que a aprendizagem é gerada pelo conhecimento criado a partir da transformação da experiência, gerando um conhecimento ou aprendizado que é adquirido por meio da prática ou da observação (Kolb \& Kolb, 2005). A análise à luz dessa teoria justifica-se no entendimento de que a ABP é percebida como um dos métodos que podem ser utilizados no escopo da aprendizagem experiencial (Efstratia, 2014).

Já a análise da área contábil é justificada com base em evidências anteriores (Silva \& Bruni, 2017) que indicam o uso frequente de metodologias passivas e a necessidade de que os docentes busquem práticas que possibilitem capacitar o estudante para a futura atuação profissional. Especificamente em disciplinas relacionadas à contabilidade gerencial, os discentes percebem a importância de terem contato com métodos práticos e casos reais (Viegas, Paes, Gouveia, Tractenberg, \& Kurtz, 2018).

Ao considerar estudos anteriores, como os de Silva e Bruni (2017) e Viegas et al. (2018), propõe-se discutir sobre a aplicação de uma metodologia que poderá propiciar melhorias na formação do profissional contábil. Pretende-se também corroborar e avançar aos achados anteriores (Azevedo et al., 2017; Silva et al., 2018) investigando além do desenvolvimento de competências, a percepção geral de discentes quanto a outros benefícios e/ou limitações referentes ao uso do método ABP. Entende-se ainda como contribuição a análise da visão de pós-graduandos, público que não havia sido investigado nos estudos mencionados anteriormente e que terão a oportunidade de experienciar uma metodologia ativa, a qual poderão usar futuramente, visto que muitos deles atuam ou desejam atuar na docência.

\section{REFERENCIAL TEÓRICO}

\subsection{A Aprendizagem Baseada em Projetos e a Aprendizagem Experiencial}

A concepção do ensino baseado em projetos emergiu na década de 1920, sendo Jonh Dewey e William Kilpatrick os pesquisadores responsáveis pelo início desse tipo de aprendizagem que, a princípio, visava uma maior participação dos estudantes, mas, com o tempo, passou a ser vista também na perspectiva de investigação em busca do conhecimento (Behrens, 2014). Para Barbosa e Moura (2013), essa tipologia de aprendizagem, que é tida como aprendizagem baseada em projetos, pode ser considerada como uma metodologia ativa que possibilita aos estudantes a construção de competências. 
Sintetizando resultados que podem ser alcançados com o uso do ABP no ensino superior, Guo et al. (2020), por meio de um estudo de revisão, observaram que a metodologia pode interferir em aspectos cognitivos, por exemplo, na compreensão sobre o assunto ensinado; na parte afetiva, o que pode ser visto, por exemplo, na satisfação do discente durante o aprendizado e ainda no aspecto comportamental, o que pode ser percebido no desenvolvimento de habilidades/competências. Com base nesses achados, os autores enfatizaram que a ABP tem potencial de contribuir com uma aprendizagem mais inovadora, atendendo demandas do ensino superior na preparação dos estudantes para o exercício profissional.

A ABP tem como uma de suas características principais inserir os estudantes em um processo de investigação que possibilitará a aquisição do conhecimento (Blumenfeld et al., 1991; Bell, 2010). Assim, essa metodologia pode ser entendida como "uma abordagem orientada para o estudante, facilitada pelo professor" (Bell, 2010, p. 39), na qual está inserida uma questão principal a ser investigada pelos estudantes com acompanhamento do professor, o que deverá resultar na elaboração de um projeto.

Lattimer e Riordan (2011) acrescentaram que, na ABP, os estudantes buscam, por meio da investigação, respostas para questões do mundo real. Em concordância, Barbosa e Moura (2013) destacam que a existência de casos reais é uma pressuposição dessa metodologia, que proporciona maior aprendizado quando comparada aos modelos tradicionais de ensino. De modo mais amplo, Vesikivi, Lakkala, Holvikivi e Muukkonen (2019) destacaram que a ABP permite a integração do conhecimento, e quando adotada inteiramente no currículo do curso tem potencial de contribuir para reduzir a retenção de estudantes no início do curso.

A presença de situações reais (práticas) no desenvolvimento da ABP propicia o envolvimento dos estudantes no processo de investigação, instigando a inovação para resolver a problemática proposta (Larmer \& Mergendoller, 2010). Nesse sentido, destaca-se a sua aproximação com a Teoria da Aprendizagem Experiencial. Segundo Kolb e Kolb (2005), a partir dessa teoria, a aprendizagem é discutida na perspectiva de ser obtida por experiências em um processo com quatro princípios, quais sejam: experienciar, refletir, pensar e agir. Os autores apontam que, segundo a Teoria da Aprendizagem Experiencial, a aprendizagem é um processo no qual o conhecimento é criado e recriado a partir da transformação da experiência, gerando um conhecimento ou aprendizado que é adquirido a partir da prática ou da observação (Kolb \& Kolb, 2005).

De acordo com Kolb e Kolb (2005), o modelo de aprendizagem experiencial consiste em um ciclo composto por quatro diferentes estágios integrados. Esses estágios são compostos por dois modos relacionados à 'Experiência Concreta' e 'Conceituação Abstrata', além de dois modos relacionados à 'Observação Reflexiva' e 'Experiência Ativa'. Tais estágios são caracterizados por Gil (2008), significando que o ciclo se inicia pela experiência (Experiência Concreta), que serve de base para a reflexão (Observação Reflexiva) que, aliada a uma teoria (Conceituação Abstrata), faz com que hipóteses sejam criadas a fim de serem testadas em novas situações (Experimentação Ativa). Ao trazer essa discussão para o âmbito do processo educacional, o autor defende que a aprendizagem experiencial promove a aproximação da teoria com a prática, já que permite que conceitos abstratos tenham significado ao serem confrontados com as situações práticas do dia a dia.

Nesse sentido, Merriam e Bierema (2013) reforçam que a aprendizagem experiencial está relacionada ao processo que se dá quando teorias são associadas às experiências, a partir de práticas reflexivas, ou à aprendizagem baseada na prática. Assim, a aprendizagem experiencial compreende um conjunto de mecanismos que oferece aos indivíduos experiências capazes de estimulá-los a aprender. Contudo, torna-se relevante reforçar que as experiências não têm valor garantido, o que implica que os indivíduos podem ter impressões diferentes acerca de uma 
mesma experiência, pois a experiência se dá pela interação entre as suas experiências anteriores com o momento presente (Sonaglio, Godoi \& Silva, 2013).

Behr e Temmen (2012) defendem que para uma experiência ser significativa é importante reconhecer que o conhecimento não deve ser simplesmente compartilhado com as pessoas, pois é preciso incentivá-las a atuar em favor do seu próprio aprendizado. A pesquisa realizada por Ferreira, Leal e Farias (2020) investigou a aprendizagem experiencial proporcionada pela prática do estágio docência na área contábil, os resultados evidenciaram que as experiências vivenciadas nas atividades do estágio pelos pós-graduandos contribuíram para que eles conhecessem as metodologias de ensino e como aplicá-las na atuação docente.

Em termos práticos, nota-se que a aplicação da aprendizagem experiencial tende a ser dificultada por alguns aspectos, como o tamanho das turmas, o tempo e a resistência dos docentes, conforme apontando no estudo de Wurdinger e Alisson (2017). Esses autores investigaram a percepção de docentes de ensino superior, os quais relataram usar poucos métodos que possam ser considerados como aprendizagem experiencial, mesmo acreditando que esse tipo de aprendizagem contribui para o desenvolvimento de habilidades dos discentes.

$\mathrm{Na}$ análise específica da aprendizagem experiencial no campo da educação contábil, Gittings, Taplin e Kerr (2020) verificaram que a implementação de atividades experienciais em instituições de ensino superior, na Austrália, ocorreu na perspectiva de promover habilidades que são demandadas no exercício da profissão contábil. Os autores ressaltaram ainda que a aprendizagem experiencial contribui para o conhecimento, satisfação do discente e oportunidade de aplicação da teoria na prática.

Diante do exposto, objetiva-se, no presente estudo, analisar a aplicação da ABP sob a luz da Teoria da Aprendizagem Experiencial, visto que o método envolve a resolução de problemas e promove a integração entre a teoria e a prática. No próximo tópico, apresentam-se as etapas adotadas para o desenvolvimento da ABP.

\subsection{Etapas do Desenvolvimento da Aprendizagem Baseada em Projetos}

No que tange ao desenvolvimento da ABP, Blumenfeld et al. (1991) ressaltaram a existência de uma questão norteadora para desenvolver as atividades, além de um produto final gerado por essas atividades, como aspectos principais dos projetos. Já Larmer e Mergendoller (2010) evidenciaram que, para maior qualidade e relevância dos projetos, é necessário que os alunos os percebam como significativos e que haja alcance de um propósito educacional.

Larmer e Mergendoller (2010) defenderam ainda oito características fundamentais para aprendizagem baseada em projetos. Para os autores, é preciso que: i) os estudantes percebam que o conteúdo é significativo; ii) os estudantes entendam que é necessário saber para responder ao problema; iii) exista uma questão de condução que contemple aspectos principais do tema a ser aprendido; iv) os estudantes tenham participação ativa na escolha do projeto e, assim, vejam mais significado; v) exista a possibilidade de aquisição de competências do Século XXI, como criticidade, cooperação, comunicação, criatividade; vi) exista um inquérito profundo sobre uma situação real; vii) haja crítica e revisão por parte do professor e entre os estudantes com o intuito de imprimir mais qualidade ao projeto final; viii) existência de um público interessado no projeto que dê mais significado para os projetos.

Destaca-se que, para o desenvolvimento da $\mathrm{ABP}$, é necessário que algumas etapas sejam realizadas, quais sejam: 
Planejamento - Quando os estudantes apresentam uma proposta de como desenvolverão suas atividades para realizar o projeto.

Execução - Quando os estudantes realizam as atividades de pesquisa e de organização das informações para realizar o projeto.

Análise e Depuração - Quando os estudantes apresentam as informações que já conseguiram obter e já está em andamento o início de uma estrutura do projeto.

Apresentação - Quando os estudantes devem evidenciar a proposta para resolver a questão direcionadora do projeto que havia sido aventada pelo professor. Nesse momento, os estudantes devem também compartilhar suas ideias junto aos colegas e professores, analisando os resultados alcançados com a atividade.

Avaliação - Quando os estudantes irão se autoavaliar e avaliar seus colegas. Assim, eles poderão verificar em quais partes do projeto tiveram melhor desempenho e em quais poderiam buscar melhorias.

Figura 1. Etapas da ABP

Fonte: Elaborada com base em Bento (2011)

É importante ressaltar que, na ABP, o papel do professor deve ser o de facilitar e orientar, não apenas o de transmitir informações, como ocorre em aulas tradicionais, o que pode gerar desafios para os quais ele deve estar preparado (Bender, 2014). Dessa forma, durante toda a aplicação da ABP, o professor deverá atuar como mediador no processo de ensino e deverá, ainda, evidenciar com clareza a forma como se dará a aprendizagem e a avaliação da mesma (Nascimento, Behrens \& Torres, 2016).

A partir da análise da ABP, observa-se que, para seu desenvolvimento, é demandado que o aluno participe ativamente e que tenha certo conhecimento e persistência. Nesse sentido, os professores são essenciais para auxiliar os estudantes na construção do conhecimento (Blumenfeld et al., 1991). Como benefícios, os estudantes poderão, a partir do uso da ABP, ter um aprendizado mais significativo e desenvolver habilidades e competências (Barbosa \& Moura, 2013).

Considerando a aprendizagem baseada em projetos, o estudo de Azevedo et al. (2017) objetivaram identificar conhecimentos, habilidades e atitudes desenvolvidas por discentes de Contabilidade por meio da ABP na disciplina de Orçamento Empresarial. Os autores verificaram, segundo relato dos alunos, que houve mais aquisição de conhecimento na área contábil e gerencial, que as principais habilidades foram o trabalho em equipe, o planejamento e a visão sistêmica e quanto as atitudes destacaram o comprometimento, a proatividade e o respeito frente a opiniões diferentes.

De modo similar, Silva et al. (2018) investigaram a ABP em um curso de Ciências Contábeis, especificamente, na disciplina Controladoria. Os pesquisadores identificaram que estudantes perceberam o desenvolvimento de habilidades, competências e atitudes com o uso da $\mathrm{ABP}$, o que pode contribuir para a formação profissional, porém, mesmo com tais benefícios, os estudantes mostraram preferência pelas abordagens tradicionais de ensino.

Por fim, destaca-se o estudo de Parrado-Martínez e Sánchez-Andújar (2020) o qual investigou o desenvolvimento de competências associados ao uso da ABP em um curso de especialização em finanças. A análise realizada por meio de um experimento, durante dois anos, possibilitou verificar melhorias significativas nas competências analisadas (habilidades de planejamento e organização, trabalho em equipe e cooperação; capacidade de gestão da informação; competência comunicativa oral; criatividade e competências de inovação) após o uso da ABP. A maioria dos discentes mostraram-se satisfeitos com a metodologia, destacando ser uma forma motivadora, que propicia mais autonomia e possibilita visualizar aspectos teóricos em situações reais. 


\section{PROCEDIMENTOS METODOLÓGICOS}

Para alcance do objetivo proposto, desenvolveu-se um estudo descritivo com abordagem qualitativa. A ABP foi aplicada na disciplina 'Análise de Custos' em um Programa de PósGraduação em Ciências Contábeis na modalidade stricto sensu. A coleta de dados ocorreu por meio da análise documental, observação, aplicação de questionário e grupo focal (entrevista conjunta) com a participação dos estudantes matriculados na referida disciplina.

Destaca-se que houve um acompanhamento das pesquisadoras durante todo o processo de aplicação da ABP na disciplina. Contudo, antes de iniciar esse processo, todos os discentes foram comunicados sobre a realização da pesquisa e qual era seu objetivo, também tiveram acesso ao termo de esclarecimento livre e esclarecido, conforme disposições éticas da instituição, assim, somente após o aceite de todos discentes é que as pesquisadoras iniciaram os procedimentos para coleta de dados.

Ainda referente aos dados analisados, é pertinente pontuar que o presente estudo se difere de outros (Azevedo et al., 2017; Silva et al., 2018) na escolha do público, pois analisa discentes de pós-graduação stricto sensu. Essa escolha mostra-se relevante, pois segundo Leal e Oliveira (2018) esse público também necessita de aprender com outros métodos de ensino que não sejam só os tradicionais e que apresentem inovação, contribuindo para desenvolvimento de outras habilidades, além do aprendizado. Já a disciplina de Análise de Custos, foi selecionada devido suas características que instigam a demanda por casos reais e conexão com a prática profissional (Viegas et al., 2018), o que é esperado com o uso da ABP.

A amostra é composta de 14 alunos matriculados na disciplina, sendo esses mestrandos e doutorandos. Importante ressaltar que essa disciplina é ofertada como optativa e tem uma carga horária de 60 horas. Para início do desenvolvimento da $\mathrm{ABP}$, a professora responsável pela disciplina apresentou, durante uma das aulas, o que é a metodologia $\mathrm{ABP}$ e como ela seria utilizada, evidenciando as etapas gerais a serem seguidas na aplicação da técnica, conforme exposto no referencial deste trabalho (Bento, 2011). A docente explicou também que o tema a ser trabalhado com a ABP era a "adoção da gestão estratégica de custos nas organizações", que é a temática principal da disciplina.

A questão direcionadora da ABP proposta pela professora para a turma foi: "Como a empresa analisada poderá utilizar a Gestão de Custos para controle, planejamento e processo decisorial?". Para possibilitar o trabalho de diferentes tópicos que contemplam a gestão estratégica de custos, a professora indicou que os alunos escolhessem para os projetos as seguintes temáticas: i) determinantes na formação de preço; ii) gestão e mensuração dos custos de qualidade; iii) gestão de custos interorganizacionais; iv) análise dos custos dos concorrentes.

Para essa atividade, os alunos se organizaram em quatro grupos, tendo sido dois deles formados por quatro componentes e dois formados por três componentes. Em seguida, cada grupo escolheu um tópico para desenvolver a ABP. Durante a apresentação da aplicação da $\mathrm{ABP}$ na disciplina, a professora indicou com mais detalhes as etapas (Tabela 1) que seriam desenvolvidas. 
Tabela 1

\section{Etapas de Aplicação da ABP na disciplina de Análise de Custos}

\begin{tabular}{l|l}
\hline \multicolumn{1}{c}{ Etapas } & \multicolumn{1}{c}{ Atividades } \\
\hline 1. Escolha da empresa para realização do projeto & $\begin{array}{l}\text { Os grupos escolheram a empresa e verificaram a } \\
\text { viabilidade da realização do trabalho. }\end{array}$ \\
\hline $\begin{array}{l}\text { 2. Apresentação da proposta (planejamento) inicial do } \\
\text { projeto }\end{array}$ & $\begin{array}{l}\text { Foi estabelecido um cronograma para as apresentações } \\
\text { da proposta inicial do projeto e da empresa } \\
\text { selecionada. }\end{array}$ \\
\hline 3. Apresentação da primeira versão do projeto & $\begin{array}{l}\text { Os grupos apresentaram a problemática identificada } \\
\text { para o projeto, a estrutura e o planejamento para o } \\
\text { desenvolvimento (Análise e Depuração). }\end{array}$ \\
\hline 4. Acompanhamento & $\begin{array}{l}\text { A professora responsável pela disciplina agendou } \\
\text { atendimentos aos grupos para esclarecimento de } \\
\text { dúvidas e acompanhamento da construção do projeto. }\end{array}$ \\
\hline 5. Apresentação do Projeto & $\begin{array}{l}\text { A apresentação final do projeto foi por meio de vídeo } \\
\text { construído pelos grupos. }\end{array}$ \\
\hline 6. Avaliação da ABP & $\begin{array}{l}\text { Foi realizada a avaliação por pares, autoavaliação e } \\
\text { grupo focal (avaliação conjunta). Ocorreu também a } \\
\text { avaliação da professora para cada projeto. }\end{array}$ \\
\hline
\end{tabular}

Fonte: Dados da pesquisa (2019)

A etapa de avaliação sobre o uso da ABP foi realizada por meio da aplicação de um questionário de autoavaliação, de modo que cada aluno atribuiu uma nota, considerando seu desempenho no desenvolvimento da ABP. Esse formulário foi elaborado com base na literatura, considerando as etapas de desenvolvimento do projeto, englobando: produtividade, comprometimento, conhecimento das etapas, trabalho em equipe, conteúdo, habilidades e, ainda, competências desenvolvidas.

Os alunos também responderam um formulário de avaliação dos colegas (pares), ou seja, cada um avaliou, por meio de notas, todos os componentes do grupo do qual ele participou. Os itens de avaliação visavam mensurar como cada colega se portou mediante as atividades propostas, se cumpriu o prazo, se participou conforme planejamento, se colaborou de forma ativa e qual foi o desempenho geral.

É importante ressaltar que em todas as etapas propostas para o desenvolvimento dos projetos a professora participou, principalmente para dar orientações sobre direcionamentos e para sanar dúvidas. Foram agendados atendimentos, por meio de reuniões extraclasse, conforme necessidades dos grupos.

O grupo focal foi realizado com todos os estudantes, (indicados como P1, P2...) tendo eles, nesse momento, a oportunidade de relatar a percepção quanto ao aprendizado com a ABP. As questões direcionadas aos estudantes permitiram averiguar possíveis benefícios obtidos e habilidades desenvolvidas com o uso dessa metodologia, especialmente, quando comparada a métodos tradicionais de ensino, tendo sido levado em conta a forma de planejamento e possíveis dificuldades com o uso da $\mathrm{ABP}$ e, ainda, percepção quanto à vivência prática atrelada ao aprendizado teórico. Os estudantes apresentaram também as principais limitações evidenciadas no desenvolvimento das etapas dos projetos.

Estando todos os dados coletados organizados, apresentou-se a análise descritiva referentes à autoavaliação e avaliação entre pares. Em seguida, as informações obtidas por meio do grupo focal foram apresentadas por meio da análise de conteúdo, conforme propõe Bardin (2011) com a realização da pré-analise, exploração do material e tratamento dos resultados, o que permitiu evidenciar os relatos dos estudantes em duas categorias, as quais indicaram benefícios e limitações no uso do método ABP. 
Em síntese, os resultados do presente artigo foram organizados em três seções, da seguinte maneira: (i) desenvolvimento da ABP, revelando como foi o processo ao longo do semestre, as apresentações e resultados alcançados por cada grupo, tudo descrito com base na observação e análise documental dos materiais elaborados pelos discentes; (ii) avaliação da ABP, indicando os resultados dos formulários de autovaliação, avaliação dos pares e avaliação da docente da disciplina; e (iii) benefícios e limitações na aplicação da ABP, os quais foram demonstrados a partir da análise de conteúdo, realizada sobre o relato dos discentes capturado por meio do grupo focal.

\section{ANÁLISE DOS RESULTADOS}

\subsection{Desenvolvimento da ABP}

Conforme apresentado na metodologia (Tabela 1), foram desenvolvidas seis etapas para a aplicação da ABP na disciplina Análise de Custos. Após a escolha da empresa para a realização do projeto, os alunos apresentaram em sala de aula, em uma data previamente estabelecida, a proposta inicial do projeto. Como resultado, foram evidenciadas as características da empresa e os principais aspectos relacionados ao uso da gestão estratégica de custos, abordando cada grupo uma temática específica. Nesse momento, a professora ressaltou a necessidade de deixar claro como a empresa poderá adotar o projeto que será proposto e que os alunos tenham o cuidado de detalhar todas as etapas que foram realizadas e/ou propostas. Os colegas também indicaram sugestões para os projetos apresentados dos outros grupos.

Além disso, verificou-se que, dos quatro grupos, dois estavam com objetivos já definidos e as empresas selecionadas, os outros dois grupos relataram dificuldades para selecionar as empresas. Assim, a professora forneceu algumas orientações e dicas para que os alunos conseguissem ter acesso às organizações, bem como esclareceu algumas questões estruturais do trabalho.

Ademais, foi agendado pela professora um atendimento aos grupos para acompanhamento no desenvolvimento das etapas do projeto, tendo sido percebido que os alunos apresentaram muitas dúvidas, o que se deve ao desconhecimento quanto a essa metodologia. A professora da disciplina entregou aos alunos um roteiro com explicações a respeito de como funciona a $\mathrm{ABP}$, evidenciando o objetivo de utilizá-la na disciplina e quais quesitos seriam avaliados.

$\mathrm{Na}$ etapa de 'análise e depuração', os alunos apresentaram algumas informações a respeito da empresa escolhida e alguns procedimentos que adotariam para conseguir responder a problemática proposta. Essa apresentação ocorreu no horário das aulas e todos os discentes assistiram uns aos outros. Nesse momento, a professora transmitiu algumas informações relacionadas à estrutura da apresentação, enfatizando a necessidade de deixar mais detalhado como seria a elaboração projeto.

Importante ressaltar que, na aplicação da ABP em sala de aula, o professor não deve ser impositivo, devendo ele atuar como um orientador de forma que os alunos consigam resolver as situações de forma mais independente (Bender, 2014). Essa maior autonomia dos alunos em busca do próprio aprendizado deverá ser incentivada pelo professor, sendo necessário, portanto, que ele se prepare, pois também desempenhará papel diferente se comparado com o papel exercido durante aplicação dos métodos tradicionais de ensino (Bender, 2014).

Posteriormente, na etapa da 'apresentação do projeto', os alunos apresentaram todo o processo de desenvolvimento da ABP e, para tanto, eles prepararam um vídeo que foi exposto para toda a turma. O tempo do vídeo foi delimitado pela professora, os estudantes organizaram a 
gravação considerando as principais etapas do projeto, incluindo: caracterização da empresa; situação-problema; proposta do projeto e apresentação dos resultados.

Conforme descrito na metodologia, cada grupo tratou de uma temática específica que se inseria na temática geral de gestão estratégica de custos. $\mathrm{O}$ resumo de cada projeto é exposto na Tabela 2.

Tabela 2

\section{Resumo dos resultados da ABP}

\begin{tabular}{|c|c|c|}
\hline Grupos - temática específica & Atuação da empresa & Principais resultados \\
\hline $\begin{array}{l}\text { G1 - determinantes na } \\
\text { formação de preço }\end{array}$ & Ensino & $\begin{array}{l}\text { Análise dos fatores determinantes da formação de preço } \\
\text { da mensalidade cobrada no curso de Ciências Contábeis } \\
\text { em uma instituição de ensino particular, com a proposta } \\
\text { de determinação do preço focado em custos. }\end{array}$ \\
\hline $\begin{array}{l}\text { G2 - gestão e mensuração } \\
\text { dos custos de qualidade }\end{array}$ & Cosméticos & $\begin{array}{l}\text { Análise de fatores que afetam os custos da qualidade na } \\
\text { elaboração de produtos depilatórios com a proposta de } \\
\text { estabelecer um canal com os clientes para registro de } \\
\text { sugestões, bem como mudanças em algumas práticas da } \\
\text { empresa. }\end{array}$ \\
\hline $\begin{array}{l}\text { G3 - gestão de custos } \\
\text { interorganizacionais }\end{array}$ & Agronegócio & $\begin{array}{l}\text { Análise dos custos com proposta da oferta de refeições } \\
\text { em uma unidade da empresa, com aproveitamento de } \\
\text { recursos próprios localizados em outro local pertencente } \\
\text { à mesma empresa. }\end{array}$ \\
\hline $\begin{array}{l}\text { G4 - análise dos custos dos } \\
\text { concorrentes }\end{array}$ & Atacadista & $\begin{array}{l}\text { Análise do setor atacadista com a proposta de modelo } \\
\text { para análise de custos de concorrentes da empresa. }\end{array}$ \\
\hline
\end{tabular}

Fonte: Dados da pesquisa (2019)

Após realizada a apresentação pelos grupos, a professora reforçou que todo projeto deve ter uma análise fundamentada que evidencie efetivamente a viabilidade de execução, bem como os benefícios de sua implementação. Cabe ressaltar também que, mesmo com as especificidades, cada grupo contemplava um tema geral (gestão estratégica de custos) com um objetivo previamente estabelecido. Na visão de Larmer e Mergendoller (2010), a existência de uma questão principal e de um objetivo educacional são essenciais no desenvolvimento do ABP.

\subsection{Avaliação da ABP}

O processo de avaliação da aplicação ABP analisada na presente pesquisa comportou a autoavaliação dos alunos, a avaliação entre pares e a avaliação da professora da disciplina, ou seja, buscou-se identificar a percepção dos alunos quanto ao próprio desempenho, considerando as possíveis habilidades desenvolvidas com o uso da metodologia e, também, o desempenho dos colegas. As respostas são apresentadas, a seguir, na Tabela 3.

Tabela 3

\section{Autoavaliação de Desempenho}

\begin{tabular}{|c|c|c|c|}
\hline Produtividade & Máx. & Mín. & Méd. \\
\hline Procurei conhecer o trabalho a ser executado & 10 & 9 & 9.75 \\
\hline Cumpri os prazos estabelecidos & 10 & 8 & 9.61 \\
\hline Realizei o trabalho com a qualidade estabelecida & 10 & 8 & 9.18 \\
\hline Média por item & & & 9.51 \\
\hline \multicolumn{4}{|l|}{ Comprometimento } \\
\hline Conheço os objetivos propostos para o trabalho (ABP) & 10 & 8 & 9.25 \\
\hline Executei minhas atividades alinhadas aos objetivos propostos & 10 & 7 & 9.36 \\
\hline Contribuí para a melhoria da execução das atividades & 10 & 7 & 9.18 \\
\hline
\end{tabular}


Cumpri os compromissos estabelecidos na execução das atividades

Média por item

\section{Conhecimento das Etapas do Trabalho}

\begin{tabular}{|c|c|c|c|}
\hline Desempenhei o trabalho com conhecimento sobre os procedimentos/etapas propostas & 10 & 8 & 9.00 \\
\hline Busquei conhecer as instruções necessárias para a execução do trabalho & 10 & 8 & 9.14 \\
\hline Executei o trabalho conforme as etapas e objetivos definidos & 10 & 8 & 9.14 \\
\hline Média por item & & & 9.10 \\
\hline
\end{tabular}

Trabalho em Equipe

Conheço os objetivos do trabalho em equipe

$\begin{array}{lll}10 & 8 & 9.71\end{array}$

Interagi de maneira cooperativa com os membros da minha equipe

$\begin{array}{lll}10 & 8 & 9.43\end{array}$

Facilitei o relacionamento entre os membros da equipe

$\begin{array}{lll}10 & 8 & 9.36\end{array}$

Colaborei ativamente para o desempenho das atividades

$\begin{array}{lll}10 & 8 & 9.43\end{array}$

Média por item

\section{Conteúdo}

\begin{tabular}{|c|c|c|c|}
\hline A metodologia ABP me auxiliou a fixar/memorizar o conteúdo trabalhado & 10 & 0 & 8.71 \\
\hline Consegui perceber a aplicação prática do conteúdo estudado na organização & 10 & 3 & 9.14 \\
\hline A aplicação da metodologia ABP influenciou no processo ensino e aprendizagem & 10 & 3 & 9.14 \\
\hline Média por item & & & 9.00 \\
\hline \multicolumn{4}{|l|}{ Habilidades e Competências } \\
\hline $\begin{array}{l}\text { A ABP contribuiu para desenvolver a habilidade analítica no decorrer do desenvolvimento } \\
\text { da atividade }\end{array}$ & 10 & 7 & 9.29 \\
\hline Desenvolvi a habilidade de comunicação & 10 & 7 & 9.29 \\
\hline A metodologia auxiliou para a habilidade de trabalhar em equipe & 10 & 8 & 9.00 \\
\hline A aplicação da ABP contribuiu para a habilidade de resolver problemas e tomar decisão & 10 & 5 & 9.07 \\
\hline Média por item & & & 9.16 \\
\hline
\end{tabular}

Fonte: Dados da Pesquisa (2019)

Conforme pode ser visto na Tabela 3, cada aluno fez a autoavaliação nos seis itens, atribuindo uma nota de 0 a 10 para cada assertiva. Observa-se que a maior média ficou centrada no item produtividade, o que evidencia a preocupação dos alunos quanto ao cumprimento do prazo e qualidade do trabalho desenvolvido. Destaca-se também o trabalho em equipe, o qual sugere que houve uma colaboração de cada aluno com o grupo no desenvolvimento da ABP. Ademais, verifica-se que, em todos os itens, a nota foi maior que 9, indicando que, no geral, os alunos se avaliaram bem nos itens apresentados.

Adicionalmente, foi solicitado ao aluno que indicasse uma pontuação referente a sua autoavaliação geral no desenvolvimento da ABP. A menor nota atribuída foi 8, sendo 10 a maior, ficando a média em 9,15. Ao considerar a autovaliação apresentada na Tabela 3, bem como os resultados alcançados pelos projetos (Tabela 2), entende-se que os alunos tiveram um bom aproveitamento acadêmico com a aplicação da ABP. A respeito desse fato, destaca-se que, com a aplicação da ABP, é possível que os alunos participem ativamente, uma vez que estarão envolvidos na investigação e na busca por responder uma questão norteadora (Larmer \& Mergendoller, 2010).

Cabe ressaltar que o uso da aprendizagem baseada em projetos torna propício o trabalho em equipe, como apresentado por Bell (2010) e Azevedo et al. (2017). Espera-se, também, que a metodologia favoreça o desenvolvimento de competências, como: análise crítica, comunicação, liderança e relacionamento interpessoal, conforme apontamentos na literatura (Barbosa \& Moura, 2013; Larmer \& Mergendoller, 2010). 
Um aspecto a ser destacado é que, apesar das médias acima de 9, nota-se que, no item conteúdo, houve valores mínimos abaixo de 5, o que indica que nem todos os alunos perceberam efetividade ao utilizarem a metodologia para melhor fixação do conteúdo. Entende-se que esse achado possa ser explicado pelas diferentes percepções dos alunos quanto ao uso das metodologias ativas. Conforme apontado por Berbel (2011), é necessário que os discentes acreditem no método para que obtenham benefícios dele.

Os alunos responderam também um questionário que permitiu que cada um avaliasse os demais componentes do grupo do qual fazia parte. Essa avaliação centrou-se no papel dos alunos frente ao desenvolvimento da ABP.

Tabela 4

Avaliação geral por aluno (nota dos pares)

\begin{tabular}{clrrrr}
\hline & & Grupo 1 & Grupo 2 & Grupo 3 & Grupo 4 \\
\hline \multirow{3}{*}{ Cumpriu os prazos estabelecidos } & Mínimo & 10.00 & 8.00 & 6.00 & 10.00 \\
& Máximo & 10.00 & 10.00 & 10.00 & 10.00 \\
& Média & 10.00 & 9.67 & 9.15 & 10.00 \\
\hline \multirow{2}{*}{$\begin{array}{c}\text { Executou as atividades alinhadas aos } \\
\text { objetivos definidos/ planejamento }\end{array}$} & Mínimo & 8.00 & 7.00 & 5.00 & 8.00 \\
& Máximo & 10.00 & 10.00 & 10.00 & 10.00 \\
& Média & 9.50 & 9.50 & 8.58 & 9.33 \\
\hline \multirow{2}{*}{ Buscou conhecer as instruções } & Mínimo & 10.00 & 7.00 & 3.00 & 8.00 \\
necessárias para a execução do & Máximo & 10.00 & 10.00 & 10.00 & 10.00 \\
& Média & 10.00 & 9.58 & 8.54 & 9.33 \\
\hline \multirow{2}{*}{$\begin{array}{c}\text { trabalho } \\
\text { desemperei ativamente para o }\end{array}$} & Mínimo & 9.00 & 7.00 & 5.00 & 9.00 \\
& Máximo & 10.00 & 10.00 & 10.00 & 10.00 \\
& Média & 9.83 & 9.50 & 8.69 & 9.67 \\
\hline \multirow{2}{*}{ Indique o desempenho geral } & Mínimo & 9.00 & 7.00 & 5.00 & 10.00 \\
& Máximo & 10.00 & 10.00 & 10.00 & 10.00 \\
& Média & 9.83 & 9.50 & 8.71 & 10.00 \\
\hline
\end{tabular}

Fonte: Dados da pesquisa (2019)

Os valores apresentados na Tabela 4 foram segregados por grupos, os quais comportavam de três a quatro estudantes cada. No geral, observa-se que as médias são próximas, apresentando apenas o Grupo 3 notas menores, o que indica que o grupo não conseguiu trabalhar de forma cooperativa conforme o esperado. É possível notar ainda que as maiores médias foram no quesito de prazo, assim como identificado na autoavaliação, o que confirma que os alunos se empenharam em atender às demandas no prazo solicitado.

Em relação ao desempenho geral, foi possível identificar que as notas de avaliação de alguns discentes foram menores do que as notas da autoavaliação. Entende-se que isso ocorreu pela dificuldade de alguns discentes em trabalhar em grupo.

A autoavaliaçao e a avaliação dos pares foram acrescentadas à avaliação da professora da disciplina (verificada pelas pesquisadoras com a análise documental) para a constituição da nota final de cada grupo, tendo a professora considerado o relatório entregue como resultado do projeto, bem como a apresentação final realizada em sala de aula. Por fim, na média, os alunos obtiveram $84 \%$ da nota total.

Importante destacar, que no processo de avaliação da ABP, sugere-se a aplicação de mais de uma modalidade para propiciar a consolidação da análise do desempenho dos estudantes. No 
caso apresentado foram utilizadas a autoavaliação, avaliação por pares e avaliação das etapas pela professora responsável pela disciplina.

\subsection{Benefícios e Limitações na Aplicação da ABP}

A fim de buscar entender a percepção dos estudantes, realizou-se o grupo focal, apresentando-se, nesta seção, os resultados encontrados. Inicialmente, verifica-se a análise de aspectos positivos (benefícios) e negativos (limitações) da metodologia ABP em comparação com metodologias tradicionais de ensino. Pode-se observar que vivenciar a prática durante o desenvolvimento da ABP foi um aspecto frequente na fala dos participantes.

P1: Ponto forte eu acho que é vivenciar a prática, conhecer a realidade lá fora que, às vezes, a gente só fica com o exemplo de livro de algum artigo e a atividade proporcionou isso.

P2 [...] eu achei muito interessante, principalmente, ir até as empresas para a gente conhecer a realidade. A gente fica muito dentro desse ambiente fechado [...] que acho que, às vezes, a gente perde um pouco da prática.

Conforme evidenciado na literatura (Berbel, 2011; Morán, 2015) o uso de metodologias ativas possibilita ao estudante aprender com situações reais, o que pode contribuir para seu aprendizado (Nicolaides, 2012), sendo essa experiência de viver o "mundo real" uma das premissas da ABP (Lattimer \& Riordan, 2011). Nesse sentido, percebe-se a aprendizagem experiencial, segundo a qual o conhecimento é gerado a partir da transformação da experiência, gerando um aprendizado que é adquirido com a prática ou com a observação (Kolb \& Kolb, 2005).

Outro benefício mencionado pelos alunos refere-se ao aprendizado propiciado por meio do uso da metodologia, o que pode ser identificado na fala de dois estudantes.

P3: O principal não é só visualizar é fixar isso aí. Porque hoje eu não vou precisar ler um livro, um artigo pra eu lembrar o que que é o nosso tema.

P4: Eu achei a fixação muito melhor assim [...] então, eu achei que não só para o nosso grupo, mas para o grupo dos outros também a gente consegue fixar melhor o conteúdo.

P5: [...] eu acho que essa metodologia aqui é disparada muito mais efetiva. A gente precisa ouvir um profissional, precisa trazer exemplos práticos e fazer isso no formato do ABP funcionou muito bem.

A partir do relato dos estudantes, pode-se concluir que a metodologia, para alguns, contribuiu efetivamente para o aprendizado do tema investigado no projeto. Nesse sentido, verifica-se uma concordância com a literatura anterior (Barbosa \& Moura, 2013), a qual indica que a ABP pode proporcionar mais aprendizado quando comparada com métodos tradicionais. Contudo, é importante ressaltar que a percepção referente ao aprendizado não foi unânime entre os estudantes, pois, conforme identificado nas notas de autoavaliaçao, alguns estudantes não perceberam benefícios em usar a metodologia para fixar o conteúdo. Entende-se que essa percepção estava associada, principalmente, ao fato de um estudante já haver experienciado na prática o tema que estava sendo investigado. A respeito disso, vale ressaltar que os indivíduos podem ter impressões diferentes sobre uma mesma experiência, pois a experiência atual é dada pela interação entre as suas experiências anteriores com o presente (Sonaglio et al., 2013). 
Em contraposto aos comentários anteriores, alguns discentes evidenciaram limitações na aplicação da ABP.

P1: Eu acho que um ponto a melhorar é o tempo. Infelizmente, é o tempo do período da disciplina e a nota atribuída. Eu acho que tinha que ser uma nota maior [...] porque foi algo que a gente se dedicou desde o primeiro dia de aula.

P2: O ponto fraco que eu achei, eu não sei se é porque, pra nós, que trabalhamos e moramos em outras cidades, eu achei que, às vezes, ficou difícil os encontros da equipe.

P6: [...] um ponto negativo que eu acho, que eu vejo nessa metodologia, é a dificuldade de aplicar para todos os conteúdos. Eu acho que nem todos seriam aplicáveis.

Observa-se que alguns pontos não são diretamente relacionados ao método, mas às condições que são necessárias para desenvolvê-lo. Um aspecto que também pode ser considerado é que, por cursarem a pós-graduação, os estudantes têm mais atividades se comparados com os da graduação, tornando-se o espaço temporal mais relevante. Assim, o que poderia ser reavaliado é o planejamento do docente no sentido de dispor mais tempo das próprias aulas para que os discentes consigam organizar as atividades.

Conforme visto em estudos anteriores (Bender, 2014; Nascimento et al., 2016), o professor tem um papel primordial na organização da metodologia e deve indicar, de forma clara, quais são os objetivos a serem alcançados e como serão avaliados. Considerando os comentários, uma questão que o professor deve observar atentamente diz respeito à distribuição das atividades e o método de avaliação ao longo do semestre para que os estudantes não se sintam prejudicados.

Retomando a análise, é possível observar que um dos participantes indicou que uma limitação da metodologia seria que seu uso se restringe a alguns conteúdos. Assim, questionouse aos discentes a respeito da aplicação na disciplina Análise de Custos, evidenciando eles um entendimento de que a ABP é indicada para essa disciplina. Entretanto, os estudantes ressaltaram a falta da implementação do projeto, conforme as falas a seguir.

P7: [...] então, se a gente tivesse um grupo de pesquisa, por exemplo, que associasse tanto alunos da graduação quanto da pós, específico pra esse tipo de projeto poderia ter mais frutos.

P5 [...] acompanhar a implementação do projeto amadureceria a gente ainda mais porque é, cada etapa que você vai aprofundando, você vai vendo que o universo que você precisa adentrar de informação, de conhecimento, é muito maior do que o que estabelece do macro da etapa [...] eu acho que a implementação traria mais essa visibilidade, a gente vai precisar fazer muito ajuste de rota pra fazer dar certo ou pra entender que não se aplica...

Cabe mencionar que a implementação do projeto está inserida nas etapas da ABP, porém, devido a algumas limitações, como o tempo e acesso às empresas, os discentes não tiveram a possibilidade de implementar efetivamente o projeto. Entende-se que esse é um dos maiores desafios ao utilizar a ABP, pois, para implementar o projeto, é necessário organização e integração dos diversos agentes envolvidos, ou seja, professor, alunos e, inclusive, o público externo que possa estar envolvido que, na área de negócios, provavelmente, será constituído por empresários. 
Outro aspecto que apresenta potencial contribuição da ABP, ou seja, um benefício, refere-se ao desenvolvimento de habilidades que a metodologia pode trazer, o que foi percebido por alguns participantes

P8: Mas eu acho que o principal foi a autonomia pra resolver algum problema. Porque eu peguei um aplicativo de vídeo que eu nem sabia mexer e eu tive que criar autonomia...

P3: foi a criatividade... Eu tenho uma visão de que todos foram importantes, destacaram criatividade e, de alguma forma, transmitiram o conhecimento do tema investigado no projeto.

P6: [...] eu acho que uma diferença importante do ABP é a possibilidade de desenvolver habilidades diferentes, habilidades interpessoais, a própria criatividade. Pode ser extrapolada mais do que num seminário tradicional, inclusive.

Observam-se que alguns comentários estão associados à elaboração do vídeo que foi sugerido pela professora para apresentação do projeto. Os alunos evidenciaram que, por ser algo diferente do que usualmente utilizam, eles tiveram que ser mais autônomos, o que possibilitou desenvolver outras habilidades.

O desenvolvimento de competências e habilidades é retratado na literatura ao se tratar da aplicação de metodologias ativas, destacando a autonomia dos discentes (Berbel, 2011; Farias et al., 2015). Ademais, o relato dos discentes corrobora achados de estudos anteriores (Azevedo et al., 2017; Silva et al., 2018) que indicaram o desenvolvimento de competências e habilidades com o uso da ABP.

Por fim, apresenta-se alguns comentários gerais dos participantes a respeito do uso da ABP durante o semestre.

P5: É, foi interessante [...] o que eu levo como lição de trabalho em grupo na realização desse projeto é que eu acho que a gente consegue trazer mais autonomia dentro do grupo $[\ldots .$.$] a gente precisa confiar muito no que cada um entrega como sua parte...$

P6: Eu acho que o projeto, pelo menos, eu tive essa percepção. A gente tem muitas ideias e não dá para fazer todas, salvar o mundo. Então, esse foi um desafio nosso e também justamente esse conflito de ideias.

É possível inferir que os relatos são condizentes com alguns aspectos das metodologias ativas. O conflito de ideias mencionado por um participante pode ser desafiador, mas, conforme afirma Berbel (2011), com o uso das metodologias ativas, é esperado que os estudantes possam solucionar desafios, os quais são frequentes no ambiente real. Além disso, conforme discutido por Frezatti e Martins (2016), o trabalho em equipe é uma das possibilidades que os discentes poderão desenvolver ao trabalhar com metodologias que envolvem a solução de problemas, como é o caso da ABP.

\section{CONSIDERAÇÕES FINAIS}

Este estudo teve como objetivo investigar os benefícios e limitações da aplicação do método Aprendizagem Baseada em Projetos na disciplina Análise de Custos ofertada em um Programa de Pós-Graduação em Ciências Contábeis, tendo sido essa metodologia aplicada durante um semestre. Verificou-se que a aplicação da ABP propiciou alguns desafios ao docente, 
bem como para os discentes. Destaca-se que a aplicação da metodologia requer que o docente esteja apto para lidar com as dúvidas dos alunos e com as diversas formas que eles poderão apresentar para responder à questão proposta, além da organização do tempo para inserção na disciplina que, no caso analisado, tinha outras atividades previstas.

Em relação aos discentes, espera-se que eles tenham uma postura mais ativa, visto que irão lidar com situações práticas que demandam maior proatividade. Com a pesquisa, foi possível perceber que o trabalho em equipe possibilita a aquisição de habilidades para conciliar as diferentes visões que cada membro do grupo pode apresentar, tornando a interação essencial para o desenvolvimento das atividades e das etapas da ABP.

Notou-se também que um dos benefícios da metodologia é a oportunidade de aprender a partir de um contexto real e com situações práticas, o que, por conseguinte, pode contribuir para a fixação do conteúdo. Tal achado sugere que o estudo corrobora a Teoria da Aprendizagem Experiencial, evidenciando a importância de proporcionar atividades que permitam aos estudantes aprender a partir de casos reais.

Em relação as limitações, os alunos ressaltaram o pouco tempo dispensado para o desenvolvimento da metodologia. Esse resultado se assemelha ao de Wurdinger e Alisson (2017), o qual verificou que docentes também se queixam do tempo para desenvolver métodos que possibilitem a aprendizagem experiencial. Entende-se que esse pode ser um complicador, o que reforça a necessidade de planejamento, visto que o professor, provavelmente, terá que dispor de mais horários para que os discentes se reúnam e consigam desenvolver o trabalho.

Os discentes relataram ainda a possibilidade de desenvolver algumas habilidades, como análise crítica, autonomia, trabalho em equipe, relacionamento interpessoal e comunicação, o que corrobora a literatura anterior (Azevedo et al., 2017; Silva et al., 2018). Entretanto, conforme indicado por Berbel (2011), é importante que os alunos se sintam interessados e motivados, sendo indicado trabalhar com projetos que eles percebam ter utilidade na prática. Além das habilidades desenvolvidas, os pós-graduandos conheceram uma metodologia que poderão utilizar no exercício da docência, já que muitos pretendem seguir a carreira acadêmica. Destacase também que a experiência com a ABP contribuiu para a aprendizagem significativa, pois os pós-graduandos participaram ativamente a favor do seu próprio aprendizado.

Em suma, o estudo traz contribuições ao evidenciar aspectos positivos do método, bem como desafios que deverão ser considerados pelo professor no decorrer da aplicação. Evidenciase uma metodologia que difere dos métodos tradicionais e que pode ser adotada pelos docentes em busca de maior envolvimento dos alunos. Entende-se também que o uso da ABP pode ser ainda mais benéfico na área contábil, especialmente, em disciplinas relacionadas à contabilidade gerencial, ao possibilitar que os discentes tenham contato com organizações e suas práticas de gestão.

Por fim, destaca-se que o estudo apresenta algumas limitações, como ter sido analisada a aplicação do método em uma única turma e ter considerado apenas a percepção dos discentes. Além de ser uma limitação da pesquisa, é um aspecto limitador na aplicação da metodologia, pois para que essa seja utilizada de forma mais efetiva demandaria alterações nos currículos acadêmicos, visando maior integração das disciplinas. Desse modo, sugere-se, para estudos futuros, investigar a aplicação da metodologia com um maior número de turmas, com outras disciplinas, bem como analisar a percepção de docentes que já utilizaram e/ou estão utilizando o método.

\section{REFERÊNCIAS}

Azevedo, Y. G. P., Araújo, A. O., \& Medeiros, V. C. (2017). Conhecimentos, Habilidades e Atitudes Desenvolvidas Pelos Discentes de Contabilidade Através da Aprendizagem Baseada em Projetos. Revista Contabilidade, Gestão e Governança, 20(1), 153-174. 
Barbosa, E. F., \& Moura, D. G. (2013). Metodologias ativas de aprendizagem na educação profissional e tecnológica. Boletim Técnico do Senac, 39(2), 48-67.

Bardin, L. (2011). Análise de conteúdo. São Paulo: Edições.

Behrens, M. A. (2014). Metodologia de projetos: Aprender e ensinar para a produção do conhecimento numa visão complexa. Coleção Agrinho.

Behr, T., \& Temmen, K. (2012). Teaching experience - improving teacher education with experiential learning. International Journal on New Trends in Education and Their Implications, 3(3), 60-73.

Bell, S. (2010). Project-based learning for the 21st century: Skills for the future. The clearing house, 83(2), 39-43.

Bender, W. N. (2015). Aprendizagem baseada em projetos: educação diferenciada para o século $X X I$. Penso Editora.

Bento, E. D. J. (2011). Aprendizagem por projetos para o desenvolvimento de competências: uma proposta para a educação profissional. Dissertação (Mestrado em Educação), Pontifícia Universidade Católica de Campinas, Campinas.

Berbel, N. A. N. (2011). As metodologias ativas e a promoção da autonomia de estudantes. Semina: Ciências Sociais e Humanas, 32(1), 25-40.

Blumenfeld, P. C., Soloway, E., Marx, R. W., Krajcik, J. S., Guzdial, M., \& Palincsar, A. (1991). Motivating project-based learning: Sustaining the doing, supporting the learning. Educational psychologist, 26(3-4), 369-398.

Efstratia, D. (2014). Experiential education through project based learning. Procedia-social and behavioral sciences, 152, 1256-1260.

Farias, P. A. M. D., Martin, A. L. D. A. R., \& Cristo, C. S. (2015). Aprendizagem ativa na educação em saúde: percurso histórico e aplicações. Rev. bras. educ. méd, 143-150.

Ferreira, L. V., Leal, E. A., \& Farias, R. S. O. (2020). Papel do estágio docência no desenvolvimento de competências didático-pedagógicas no contexto da pós-graduação em Contabilidade. Revista de Educação e Pesquisa em Contabilidade (REPeC), 14(2), 158-176.

Frezatti, F., \& Martins, D. B. (2016). PBL ou PBLs: a customização do mecanismo de aprendizagem baseada em problemas na educação contábil. Revista de Graduação USP, 1(1), 25-34.

Gil, A. C. (2008). Didática do ensino superior. São Paulo: Atlas.

Gittings, L., Taplin, R., \& Kerr, R. (2020). Experiential learning activities in university accounting education: A systematic literature review. Journal of Accounting Education, 52, (100680), 1-13. 
Guo, P., Saab, N., Post, L. S., \& Admiraal, W. (2020). A review of project-based learning in higher education: Student outcomes and measures. International Journal of Educational Research, 102, 1-13.

Kolb, A. Y., \& Kolb, D. A. (2005). Learning styles and learning spaces: Enhancing experiential learning in higher education. Academy of management learning \& education, 4(2), 193-212.

Kokotsaki, D., Menzies, V., \& Wiggins, A. (2016). Project-based learning: A review of the literature. Improving schools, 19(3), 267-277.

Larmer, J., \& Mergendoller, J. R. (2010). Seven essentials for project-based learning. Educational leadership, 68(1), 34-37.

Lattimer, H., \& Riordan, R. (2011). Project-based learning engages students in meaningful work: Students at High Tech Middle engage in project-based learning. Middle School Journal, 43(2), 18-23.

Leal, E. A., \& Oliveira, R. L. (2018). O método de estudo de caso aplicado no ensino em cursos de pós-graduação em ciências contábeis. Revista Contemporânea de Contabilidade, 15(35), 69-87.

Merriam, S. B., \& Bierema, L. L. (2013). Adult learning: Linking theory and practice. John Wiley \& Sons.

Morán, J. (2015). Mudando a educação com metodologias ativas. Coleção mídias contemporâneas. Convergências midiáticas, educação e cidadania: aproximações jovens, 2(1), 15-33.

Nascimento, E. C., Behrens, M. A., \& Torres, P. L. (2016). A metodologia de projetos e o desafio na elaboração de novas possibilidades de propostas. Revista Contrapontos, 16(3), 518-533.

Nicolaides, A. (2012). Innovative teaching and learning methodologies for higher education Institutions. Educational research, 3(8), 620-626.

Parrado-Martínez, P., \& Sánchez-Andújar, S. (2020). Development of competences in postgraduate studies of finance: A project-based learning (PBL) case study. International Review of Economics Education, 35 (100192), 1-12.

Silva, C. M., Araújo, A. O, Vieira, E. R. F. C., \& Bispo, A. C. K. A. (2018). Análise da Efetividade da Aprendizagem Baseada em Projetos no Desenvolvimento de Competências no Ensino Superior de Contabilidade. Anais do Congresso UnB de Contabilidade e Governança, Brasília, DF, Brasil, 4.

Silva, U. B., \& Bruni, A. L. (2017). O que me ensina a ensinar? Um estudo sobre fatores explicativos das práticas pedagógicas no ensino de contabilidade. Revista de Educação e Pesquisa em Contabilidade (REPeC), 11(2), 214-230. 
Smith, P. P., \& Gibson, L. A. (2016). Project-Based Learning in Colleges of Business: Is It Enough to Develop Educated Graduates? New Directions for Teaching and Learning, 145, 41-47.

Sonaglio, A. L. B., Godoi, C. K., \& Silva, A. B. (2013). Estilos de aprendizagem experiencial e aquisição de habilidades: um estudo com discentes de graduação em administração em instituições de ensino superior. Administração: ensino e pesquisa, 14(1), 123-159.

Vesikivi, P., Lakkala, M., Holvikivi, J., \& Muukkonen, H. (2019). The impact of project-based learning curriculum on first-year retention, study experiences, and knowledge work competence. Research Papers in Education, 35(1), 64-81.

Viegas, R. O., Paes, Á. L., Gouveia, T. A., Tractenberg, L. E., \& Kurtz, R. M. (2018). A Disciplina Contabilidade Gerencial sob a Perspectiva dos Egressos do Curso de Ciências Contábeis: Importância Atribuída e Conexão com a Prática Contábil. Sociedade, Contabilidade e Gestão, 13(3), 1-13.

Wurdinger, S., \& Allison, P. (2017). Faculty perceptions and use of experiential learning in higher education. Journal of e-learning and Knowledge Society, 13(1), 15-26. 